\title{
Transcoronary infusion of cardiac progenitor cells in hypoplastic left heart syndrome: Three-year follow-up of the Transcoronary Infusion of Cardiac Progenitor Cells in Patients With Single-Ventricle Physiology (TICAP) trial
}

Suguru Tarui, MD, ${ }^{\text {a }}$ Shuta Ishigami, MD, ${ }^{\text {a }}$ Daiki Ousaka, RDCS, ${ }^{\mathrm{a}}$ Shingo Kasahara, MD, PhD, ${ }^{\mathrm{a}}$ Shinichi Ohtsuki, MD, PhD, ${ }^{b}$ Shunji Sano, MD, PhD, ${ }^{a}$ and Hidemasa Oh, MD, $\mathrm{PhD}^{\mathrm{c}}$

\begin{abstract}
Objectives: Our aim was to assess midterm safety and clinical outcomes of intracoronary infusion of cardiosphere-derived cells (CDCs) after staged palliation in patients with hypoplastic left heart syndrome (HLHS).

Methods: In this prospective, controlled study, 14 consecutive patients with HLHS who were undergoing 2- or 3-stage surgical palliations were assigned to receive intracoronary CDC infusion 1 month after cardiac surgery $(n=7)$, followed by 7 patients allocated to a control group with standard care alone. The primary end point was to assess procedural feasibility and safety; the secondary end point was to evaluate cardiac function and heart failure status through 36-month follow-up.
\end{abstract}

Results: No complications, including tumor formation, were reported within 36 months after CDC infusion. Echocardiography showed significantly greater improvement in right ventricular ejection fraction (RVEF) in infants receiving CDCs than in controls at 36 months $(+8.0 \% \pm 4.7 \%$ vs $+2.2 \% \pm 4.3 \%$; $P=.03)$. These cardiac function improvements resulted in reduced brain natriuretic peptide levels $(P=.04)$, lower incidence of unplanned catheter interventions $(P=.04)$, and higher weight-for-age $z$ score $(P=.02)$ at 36 months relative to controls. As independent predictors of treatment responsiveness, absolute changes in RVEF at 36 months were negatively correlated with age, weight-for-age $z$ score, and RVEF at CDC infusion.

Conclusions: Intracoronary CDC infusion after staged procedure in patients with HLHS is safe and improves RVEF, which persists during 36-month follow-up. This therapeutic strategy may enhance somatic growth and reduce incidence of heart failure. (J Thorac Cardiovasc Surg 2015;150:1198-208)

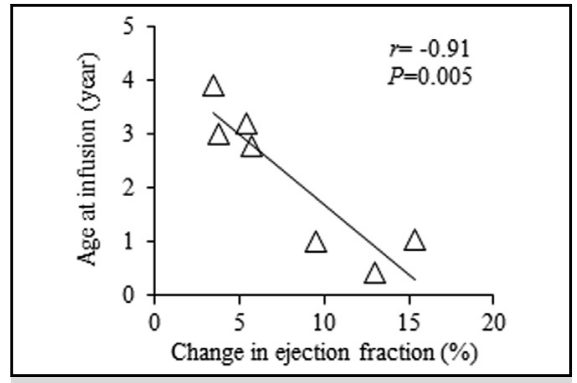

Correlation between changes in right ventricular ejection fraction and age at cardiosphere-derived cell infusion.

\section{Central Message}

This is the first clinical trial to report the midterm safety and efficacy of cardiac progenitor cell therapy in congenital heart disease.

\section{Perspective}

These preliminary results suggest that cardiac progenitor cells in younger children may secrete specific effectors to stimulate progenitor cell growth for myocardial repair. Cardiac fibrosis in congenital heart disease may be an alternative therapeutic target assessed by advanced cardiac imaging technologies to understand the mechanisms for cardiac function improvement after cell therapy.

See Editorial Commentary page 1209

See Editorial page 1023
From the Departments of a Cardiovascular Surgery and ${ }^{\mathrm{b}}$ Pediatrics, Okayama University Graduate School of Medicine, Dentistry, and Pharmaceutical Sciences, Okayama, Japan; and the ${ }^{\mathrm{c}}$ Department of Regenerative Medicine, Center for Innovative Clinical Medicine, Okayama University Hospital, Okayama, Japan. Supported by grants from the Ministry of Health, Labour and Welfare, Japan (H25-002); the Ministry of Education, Culture, Sports, Science, and Technology, Japan (C-8-1); and the Research Foundation of Okayama University Hospital, Okayama, Japan.

Read at the 95th Annual Meeting of The American Association for Thoracic Surgery, Seattle, Washington, April 25-29, 2015.
Received for publication March 23, 2015; revisions received May 26, 2015; accepted for publication June 14, 2015; available ahead of print July 29, 2015.

Address for reprints: Hidemasa Oh, MD, PhD, Department of Regenerative Medicine, Center for Innovative Clinical Medicine, Okayama University Hospital, 2-5-1 Shikata-cho, Kita-ku, Okayama 700-8558, Japan (E-mail: hidemasa@md. okayama-u.ac.jp). $0022-5223 / \$ 36.00$

Copyright $\odot 2015$ by The American Association for Thoracic Surgery http://dx.doi.org/10.1016/j.jtcvs.2015.06.076 


\begin{tabular}{|c|c|}
\hline \multicolumn{2}{|c|}{ Abbreviations and Acronyms } \\
\hline HLHS & $=$ hypoplastic left heart syndrome \\
\hline TICAP & $\begin{aligned}= & \text { Transcoronary Infusion of Cardiac } \\
& \text { Progenitor Cells in Patients with } \\
& \text { Single-Ventricle Physiology }\end{aligned}$ \\
\hline CDC & $=$ cardiosphere-derived cell \\
\hline RVEF & $=$ right ventricular ejection fraction \\
\hline cMRI & $\begin{aligned}= & \text { cardiac magnetic resonance } \\
& \text { imaging }\end{aligned}$ \\
\hline RVESV & $\begin{aligned}= & \text { right ventricular end-systolic } \\
& \text { volume }\end{aligned}$ \\
\hline RVEDV & $\begin{aligned}= & \text { right ventricular end-diastolic } \\
& \text { volume }\end{aligned}$ \\
\hline $\mathrm{Ea}$ & $=$ effective arterial elastance \\
\hline Ees & $=$ end-systolic elastance \\
\hline ITQOL- & $\begin{aligned}= & \text { Infant Toddler Quality of Life } \\
& \text { Questionnaire }\end{aligned}$ \\
\hline APCA & $=$ aortopulmonary collateral artery \\
\hline $\mathrm{BMC}$ & $=$ mononuclear bone marrow cell \\
\hline
\end{tabular}

Ð Supplemental material is available online.

Among congenital heart lesions, hypoplastic left heart syndrome (HLHS) is associated with the highest mortality. ${ }^{1}$ As management strategies for neonates and infants with HLHS have markedly evolved in recent years, ${ }^{2}$ an increasing number of patients with HLHS have survived to Fontan completion. Outcomes of patients undergoing Fontan procedures have also dramatically improved as a variety of modifications have been introduced, including lateral tunnel and extracardiac conduit variations. ${ }^{3}$ Circulation created after Fontan operation exhibits a number of physiologic limitations that have negative effects on organ system development and functionality, however, such as arrhythmia, thromboembolism, protein-losing enteropathy, plastic bronchitis, and liver fibrosis. ${ }^{4}$ Delayed somatic growth and development are also major concerns in patients with single-ventricle physiology. ${ }^{5}$ The prevalence of systolic and diastolic ventricular dysfunction continues to increase after the Fontan operation, particularly in those with morphologically right ventricles, ${ }^{6}$ and impaired ventricular function itself has been reported as an independent risk factor of an adverse outcome after the Fontan procedure. ${ }^{7}$ Moreover, a recent study has shown HLHS to be strongly associated with adverse events and late failure. ${ }^{8}$

In 2011, we conducted the Transcoronary Infusion of Cardiac Progenitor Cells in Patients with Single-Ventricle Physiology (TICAP) trial and demonstrated the feasibility of the manufacture and intracoronary delivery of cardiosphere-derived cells (CDCs) in patients with HLHS after staged palliation. This study showed that patientderived CDCs were safe and effective for improving right ventricular function, heart failure status, and somatic growth during 18 months of follow-up. ${ }^{9}$ Whether these effects could persist at 3-year follow-up and whether CDC infusion would have an impact on clinical outcomes after Fontan operation, however, remained unknown. Here we report the 36-month end point results of the TICAP trial, including cardiac function analysis and evaluation of midterm safety and outcomes after Fontan operation.

\section{MATERIALS AND METHODS}

\section{Study Design and Patient Population}

The detailed study protocol was reported previously. ${ }^{9}$ In this nonrandomized, prospective controlled study, 14 consecutive patients with HLHS were assigned to receive intracoronary CDC infusion 1 month after the cardiac surgery $(n=7)$, followed by 7 patients allocated to a control group with standard care alone. The eligible criteria was the patients under the age of 6 years old with HLHS undergoing stage- 2 or -3 palliations. Patients undergoing stage 1 reconstruction were not included due to the difficulty in coronary angiogram. Exclusion criteria were cardiogenic shock, history of pacemaker implantation, intractable arrhythmia, repeated infections, and advanced hepatic or renal insufficiency. The primary end point was to assess the procedural feasibility and safety and the secondary end point was to evaluate the right ventricular ejection fraction (RVEF) and heart failure status from the baseline through midterm follow-up. In patients allocated to receive CDCs, the atrial tissues were obtained during staged surgical palliation for autologous cell production. Clinical midterm follow-ups were scheduled at 24, 30, and 36 months. The data include 3 years of follow-up for all the patients in both CDC-treated and control groups. The study protocol of the TICAP trial was approved in December 2010 by the ethics committee of Okayama University and followed the Guidelines on Clinical Research Using Human Stem Cells issued by the Ministry of Health, Labour and Welfare, Japan. The study was performed in accordance with the Declaration of Helsinki, with written, informed consent obtained from all parents of eligible patients. This study is registered with ClinicalTrials.gov (NCT01273857).

\section{Cell Processing and Infusion}

Atrial tissues were excised, minced, and digested with $0.4 \%$ type II collagenase and $0.01 \%$ DNAse. Obtained cells were then plated in ultralow culture dishes to generate cardiospheres in Dulbecco modified Eagle medium and F12 medium supplemented with $10 \%$ autologous serum, $20 \mathrm{ng} / \mathrm{mL}$ epidermal growth factor (Sigma-Aldrich Co LLC, St Louis, $\mathrm{Mo}$ ), and $40 \mathrm{ng} / \mathrm{mL}$ basic fibroblast growth factor (Promega Corporation, Madison, Wis). Manufactured CDCs were verified by immunostaining, flow cytometry, and gene expression analysis to confirm the mesenchymal phenotype, as previously reported. ${ }^{9}$ When the specified cell dose $\left(3.0 \times 10^{5}\right.$ cells/kilogram of body weight) was achieved, CDCs were selectively infused into each coronary artery 1 month after surgical operations. During CDC infusion, the targeted coronary artery was inflated by occlusion balloon catheter Iiguman type C (Fuji Systems Corporation, Tokyo, Japan) for 2 minutes, and the cells, which were diluted in $1 \mathrm{~mL}$ for each coronary artery, were infused through the distal site of the balloon.

\section{Data Acquisition and Analysis}

Demographic characteristics, patient characteristics, preoperative assessment, and surgical characteristics were recorded from the medical records. In reporting preoperative assessment, the latest records of heart catheterization and echocardiography were used. Because all the staged palliations in both groups were performed by the same surgeon (S.S.) during follow-up, the same surgical strategies and techniques were used. 
Clinical outcomes including adverse events and catheter interventions were also collected by reviewing the medical records and through telephone interviews. Tumor formation was assessed by measuring the serum levels of tumor markers such as carcinoembryonic antigen and carbohydrate antigen 19-9, as well as carefully evaluated by echocardiography and cardiac magnetic resonance imaging (cMRI). Data regarding hemodynamic status were obtained by heart catheterization at the final follow-up examination, which was performed from 30 to 36 months of follow-up.

Cardiac function was evaluated by echocardiography at 24,30 , and 36 months of follow-up. Efficacy was also assessed by cMRI study at 36 months of follow-up in both groups. Detailed methods of cardiac function analysis were performed as previously reported. ${ }^{9}$ In short, by means of echocardiography, RVEF, right ventricular end-systolic volume (RVESV), and right ventricular end-diastolic volume (RVEDV) were calculated by the monoplane ellipsoid approximation method. Tricuspid valve annular diameter was measured by the annular diameter in the apical 4-chamber view, and $z$ score was calculated on the basis of body surface area. The same as in our previous study, ${ }^{9} \mathrm{cMRI}$ scans were performed on a Philips 1.5-T Achieva Scanner (Philips Healthcare, Netherlands) under general anesthesia. RVEF, RVEDV, and RVESV were calculated from a stack of short-axis cine images according to the disk summation method after tracing endocardial contours in end diastole and end systole. Right ventricular wall mass was calculated by tracing endocardial and epicardial contours. Mean arterial pressure, right ventricular systolic and end-diastolic pressures, RVEDV, RVESV, mean pulmonary arterial pressure, pulmonary vascular resistance index, and cardiac index were measured by catheterization study. The approximations of the stiffness of the right ventricular chamber and the ratio of effective arterial elastance (Ea) to end-systolic elastance (Ees) as a measure of ventriculoarterial coupling (Ea/Ees ratio) were calculated as previously reported. ${ }^{9}$

Heart failure status was evaluated by serum brain natriuretic peptide levels and New York University Pediatric Heart Failure Index. ${ }^{10}$ For assessment of somatic growth at each follow-up, weight-for-age $z$ scores were calculated according to the Center for Disease Control normative population data. ${ }^{11}$ Quality of life, including the condition of physical, mental, and social well-being of the patients, was assessed by means of the Infant Toddler Quality of Life Questionnaire (ITQOL-SF47). ${ }^{12}$ To identify stressful aspects of parent-child interaction, Abidin's Parenting Stress Index Short Form was used. ${ }^{13}$

\section{Statistical Analysis}

Continuous variables are expressed as mean $\pm \mathrm{SD}$. The categoric data are given as numbers or proportions. For continuous variables, the normality of data in the control group and the CDC-treated group was tested with the Shapiro-Wilk test, and comparisons were performed with the 2-tailed Student $t$ test or Mann-Whitney $U$ test, as appropriate. Categoric variables were compared with the Fisher exact test. The incidences of catheterization interventions occurring during the follow-up period were compared between the 2 groups by means of Poisson regression models. Time to first adverse event or catheterization intervention was estimated by means of the Kaplan-Meier method and compared with the logrank test. For comparison between the 2 groups by cMRI, 2-way analysis of variance was used to analyze the categoric independent variables between groups and the time interaction term within a group. To investigate predictors of cardiac functional efficacy, bivariate Pearson correlation and simple linear regression analyses were performed. The analyses were performed with SPSS software (version 22; IBM Corporation, Armonk, NY). The study funding source had no role in study design, data collection, data analysis and interpretation, or in the preparation of the manuscript.

\section{RESULTS}

\section{Patient Characteristics}

All 14 patients enrolled for this study were followed up for 36 months. The basic characteristics of the patients in both
TABLE 1. Baseline characteristics

\begin{tabular}{|c|c|c|}
\hline & Control & CDCs \\
\hline \multicolumn{3}{|l|}{ Demographics } \\
\hline Male & $5(71 \%)$ & $4(57 \%)$ \\
\hline Age at surgery $(\mathrm{y})$ & $1.5 \pm 1.7$ & $2.1 \pm 1.2$ \\
\hline Weight at surgery $(\mathrm{kg})$ & $6.8 \pm 3.8$ & $9.2 \pm 3.8$ \\
\hline \multicolumn{3}{|l|}{ Patient characteristics } \\
\hline \multicolumn{3}{|l|}{ Morphology } \\
\hline Hypoplastic left heart syndrome & $7(100 \%)$ & $7(100 \%)$ \\
\hline Mitral atresia and aortic atresia & $3(43 \%)$ & $3(43 \%)$ \\
\hline Mitral stenosis and aortic atresia & $1(14 \%)$ & $2(29 \%)$ \\
\hline Mitral atresia and aortic stenosis & 0 & $1(14 \%)$ \\
\hline Mitral stenosis and aortic stenosis & $2(29 \%)$ & 0 \\
\hline Variant (DORV, MA, hypo LV, IAA, HAA) & $1(14 \%)$ & $1(14)$ \\
\hline Restrictive ASD & 0 & $1(14 \%)$ \\
\hline Sinusoidal arteries & 0 & $1(14 \%)$ \\
\hline Aortic size before first palliation (mm) & $3.3 \pm 1.0$ & $3.6 \pm 2.0$ \\
\hline RVEF before first palliation $(\%)$ & $53.9 \pm 3.8$ & $50.4 \pm 5.2$ \\
\hline \multicolumn{3}{|l|}{ Previous cardiac surgical procedures } \\
\hline Cardiac catheter intervention & $5(71 \%)$ & $5(71 \%)$ \\
\hline Norwood operation & $6(86 \%)$ & $6(86 \%)$ \\
\hline Modified Blalock-Taussig shunt & $1(14 \%)$ & 0 \\
\hline Sano shunt & $5(71 \%)$ & $6(86 \%)$ \\
\hline Bilateral pulmonary artery banding & $2(29 \%)$ & $3(43 \%)$ \\
\hline Bidirectional Glenn procedure & $2(29 \%)$ & $4(57 \%)$ \\
\hline Cardiac arrest & 0 & 0 \\
\hline ECMO & 0 & 0 \\
\hline Genetic syndrome & 0 & 0 \\
\hline Extracardiac malformation & 0 & 0 \\
\hline Prematurity & $1(14 \%)$ & 0 \\
\hline \multicolumn{3}{|l|}{ Preoperative assessment } \\
\hline Oxygen saturation (\%) & $84.9 \pm 7.9$ & $87.8 \pm 9.9$ \\
\hline Tricuspid regurgitation greater than mild & $1(14 \%)$ & 0 \\
\hline Mean PA pressure $(\mathrm{mm} \mathrm{Hg})$ & $11.1 \pm 1.5$ & $9.9 \pm 2.8$ \\
\hline $\operatorname{RVEDP}(\mathrm{mm} \mathrm{Hg})$ & $6.5 \pm 2.1$ & $5.7 \pm 1.2$ \\
\hline PVRI (Wood units $\cdot \mathrm{m}^{2}$ ) & $1.6 \pm 0.5$ & $1.3 \pm 0.3$ \\
\hline Cardiac index $\left(\mathrm{L} / \mathrm{min} / \mathrm{m}^{2}\right)$ & $5.1 \pm 0.8$ & $4.5 \pm 2.3$ \\
\hline \multicolumn{3}{|l|}{ Surgical characteristics } \\
\hline Norwood-Glenn procedure & $1(14 \%)$ & $1(14 \%)$ \\
\hline Bidirectional Glenn procedure & $4(57 \%)$ & $2(29 \%)$ \\
\hline Total cavopulmonary connection & $2(29 \%)$ & $4(57 \%)$ \\
\hline \multicolumn{3}{|l|}{ Concomitant procedures performed } \\
\hline None & $3(43 \%)$ & $3(43 \%)$ \\
\hline Arch augmentation & $1(14 \%)$ & $1(14 \%)$ \\
\hline Tricuspid valve repair & $1(14 \%)$ & $1(14 \%)$ \\
\hline Atrial septectomy & $1(14 \%)$ & 0 \\
\hline PA patch augmentation & $1(14 \%)$ & $3(43 \%)$ \\
\hline
\end{tabular}

Data are presented as mean $\pm \mathrm{SD}$ or number (\%). $C D C$, Cardiosphere-derived cell; $D O R V$, double-outlet right ventricle; $M A$, mitral atresia; hypo $L V$, hypoplastic left ventricle; IAA, interrupted aortic arch; $H A A$, hypoplastic aortic arch; $A S D$, atrial septal defect; $R V E F$, right ventricular ejection fraction; $E C M O$, extracorporeal membrane oxygenation; $P A$, pulmonary artery; $R V E D P$, right ventricular end-diastolic pressure; $P V R I$, pulmonary vascular resistance index.

groups are outlined in Table 1. There was no significant difference in age or body weight at baseline. No differences were seen in potential risk factors, such as history of cardiac arrest, induction of extracorporeal membrane oxygenation, 
restrictive atrial septal defect for which balloon atrial septectomy was necessary, sinusoid arteries, aortic size, right ventricular function before first palliation, genetic syndromes, extracardiac malformation, and prematurity. The morphology of all of the patients was HLHS, and mitral atresia combined with aortic atresia was the most common subtype in both groups. One HLHS variant was included in each group. All the patients had undergone initial palliation, including Norwood operation or bilateral pulmonary artery banding. One patient in the control group and 2 patients in the CDC-treated group underwent a Norwood operation after bilateral pulmonary artery banding. In the Norwood operation, a Sano shunt (right ventriclepulmonary artery conduit) was used in all of the patients apart from 1 in the control group who underwent the Norwood procedure at another hospital. Stage 2 palliation was completed in 2 patients in the control group and 4 patients in the CDC-treated group before study enrollment. No significant difference in preoperative hemodynamic data was seen between the 2 groups. For staged palliative operation during which atrial tissues were obtained for cardiac progenitor cell production, 2 patients in the control group and 4 patients in the CDC-treated group underwent total cavopulmonary connection. Stage 2 palliation was performed in the rest of the patients, including the Norwood-Glenn procedure in 1 patient in each group. There were no differences in cardiopulmonary bypass time and aortic crossclamp time between the 2 groups.

\section{Safety and Adverse Events}

No complications associated with cell infusion, including sustained myocardial ischemia and ventricular arrhythmia and prolonged infection, were reported within 36 months. No evidence of tumor formation was detected by echocardiography and cMRI, and serum levels of tumor markers such as carcinoembryonic antigen and carbohydrate antigen 19-9 remained within their normal ranges 3 years after cell infusion (Figure 1, A). We assessed the late adverse events in both groups (Table 2). One patient in the control group had heart failure develop (New York Heart Association class III-IV) because of prolonged impaired ventricular function, and this patient had a history of cardiopulmonary resuscitation. Another patient in the control group had a history of prolonged chest tube drainage and finally had protein-losing enteropathy develop. No adverse events occurred in the CDC-treated group. The adverse eventfree survival curve showed no significant difference between the 2 groups (Figure 1, B).

\section{Clinical Outcomes and Hemodynamic Status}

Among 8 patients who underwent stage 2 palliation, 7 had undergone the Fontan operation during the follow-up period (Table 3). One patient in the control group, mentioned previously, still continued to have a Glenn circulation because of impaired ventricular function and poor weight gain. Fenestration was created in all patients. Catheterization study at final follow-up revealed no differences in mean pulmonary arterial pressure, right ventricular end-diastolic pressure, and pulmonary vascular resistance index; however, cardiac indices in the CDC-treated group were significantly higher than in the control group (3.6 \pm 0.6 vs $\left.4.9 \pm 0.9 \mathrm{~L} / \mathrm{min} / \mathrm{m}^{2} ; P=.02\right)$.

\section{Catheter Intervention}

The incidences of catheter interventions during followup are shown in Table 2. The incidence of any type of unintended catheter intervention was significantly lower in the CDC-treated group than in the control group (0.52 vs 1.43 events/person-y, $P=.04$ ). No differences were seen between the 2 groups in terms of the incidences of each type of intervention, including coil embolization for aortopulmonary collateral artery (APCA) and balloon angioplasty (Table 2). However, freedom of APCA coil embolization was markedly worse in controls than in the CDC-treated group, whereas there was no significant difference in freedom from any catheter intervention (Figure 1, $C$ and $D$ ).

\section{Cardiac Functional Analyses}

Pooled data of echocardiography and cMRI-measured parameters in the 2 groups are shown in Table E1. None of the parameters at baseline differed between the CDCtreated group and the control group. In cMRI study, improvement of RVEF at 36 months from baseline was significantly greater in the CDC-treated group than in the control group $(41.8 \% \pm 5.2 \%$ vs $32.2 \% \pm 9.4 \%$; $P=.04$; Figure 2, A). The absolute changes in RVEF at 36 months from baseline were found to be greater in the CDC-treated group than in the control group $(+5.7 \% \pm$ $4.6 \%$ vs $-2.2 \% \pm 4.4 \% ; P=.04)$. Although the indices of right ventricular volumes (RVEDV index and RVESV index) and right ventricular wall masses corrected by body surface area $^{1.3}$ and end-diastolic volume were reduced relative to those at baseline, no difference was seen between the 2 groups at 36 months (Figure 2, $B$ and $C$, and Table E1).

In echocardiographic assessment, the absolute changes in both RVEF and fractional area change at 36 months from baseline were significantly greater in the CDCtreated group than in the control group $(+8.0 \% \pm 4.7 \%$ vs $+2.2 \% \pm 4.3 \% ; P=.03$; and $+5.4 \% \pm 4.1 \%$ vs $+0.8 \% \pm 2.7 \% ; P=.03$; Figure $2, D$ and $E$ ). As shown in Figure 2, $F$, the absolute changes in tricuspid valve diameter from baseline to 36 months also significantly differed between the groups. To investigate diastolic function and mechanical efficiency, we assessed the stiffness of the systemic right ventricle and ventriculoarterial coupling (Ea/Ees ratio) at final follow-up (Figure 2, G and $H$ ). The CDC-treated group showed significantly decreased right ventricular chamber stiffness and 

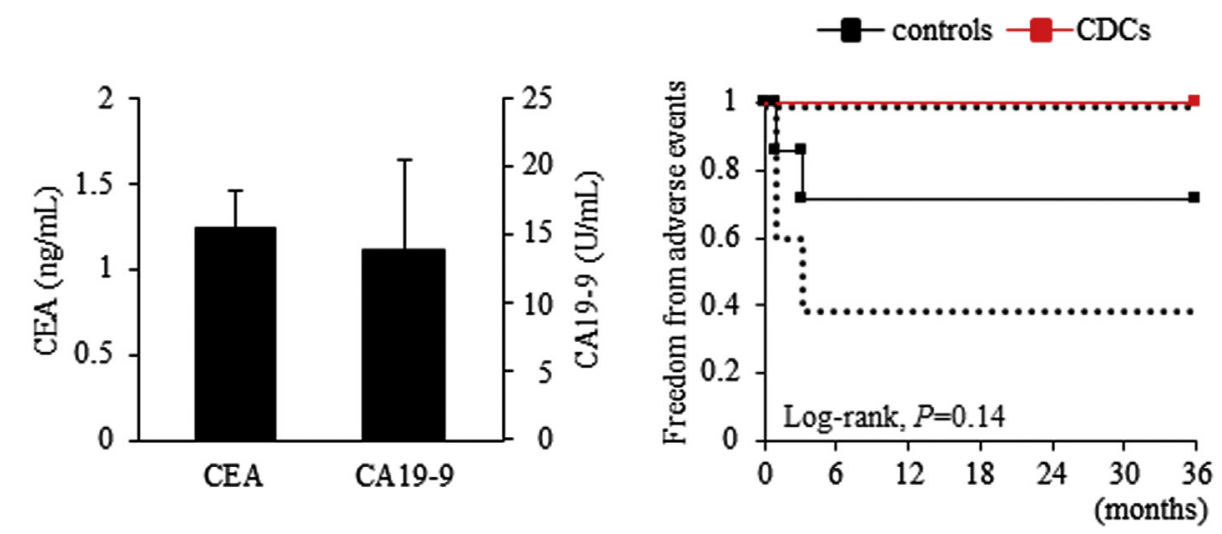

No. at risk

$\begin{array}{llllllll}\text { controls } & 7 & 5 & 5 & 5 & 5 & 5 & 5 \\ \text { CDCs } & 7 & 7 & 7 & 7 & 7 & 7 & 7\end{array}$

A

B

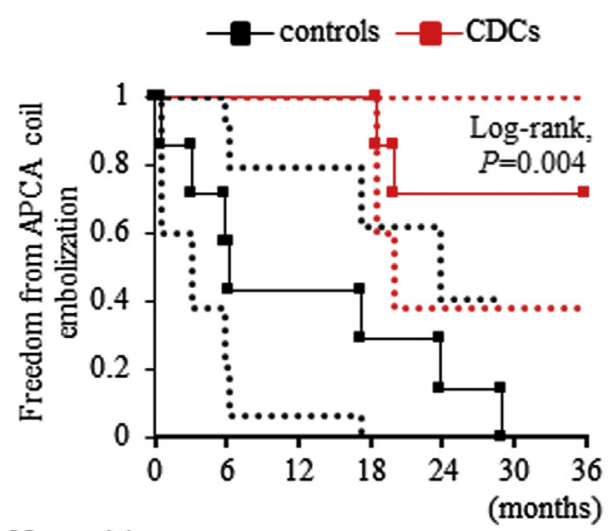

No. at risk controls $\begin{array}{llllllll}7 & 4 & 3 & 2 & 1 & 0 & 0\end{array}$

C

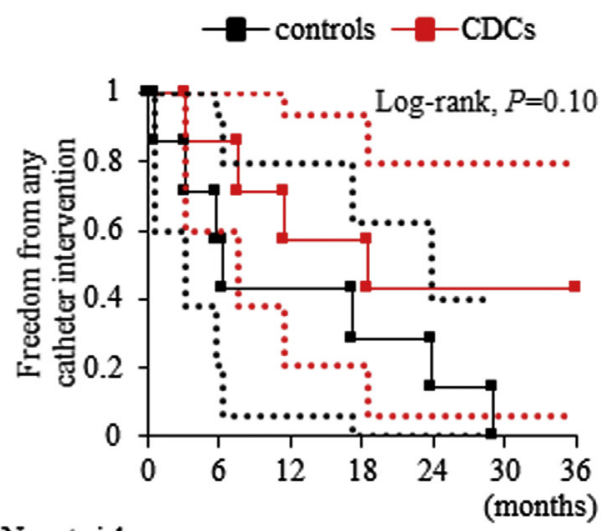

No. at risk

$\begin{array}{llllllllllllllll}\mathrm{CDCs} & 7 & 7 & 7 & 7 & 5 & 5 & 5 & \mathrm{CDCs} & 7 & 6 & 4 & 4 & 3 & 3 & 3\end{array}$

FIGURE 1. Safety and adverse events observed in Transcoronary Infusion of Cardiac Progenitor Cells in Patients with Single-Ventricle Physiology trial during 3-year follow-up. A, Serum levels of tumor markers, carcinoembryonic antigen (CEA) and carbohydrate antigen 19-9 (CA19-9), were assessed at 36 months after cardiosphere-derived cell $(C D C)$ infusion. Data are shown as mean $\pm \mathrm{SD}$. B, Kaplan-Meier adverse event-free survival curve. $\mathrm{C}$, Freedom from coil embolization for aortopulmonary collateral artery (APCA). D, Freedom from any unintended catheter intervention. Confidence interval limits (95\%) are shown as dotted lines.

Ea/Ees ratio relative to the control group $(P=.02$ and $P=.001$, respectively).

\section{Somatic Growth and Heart Failure Status}

Body weight correlated by $z$ score was analyzed to assess somatic growth during the follow-up period. The $z$ scores for weight at 36 months of follow-up were significantly higher in the CDC-treated group than in the control group $(-1.6 \pm 1.2$ vs $-3.5 \pm 1.5 ; P=.02$; Figure $3, A)$. The CDC-treated group showed lower New York University Pediatric Heart Failure Index scores and brain natriuretic peptide levels, indicating better functional status, than did the control group in the midterm $(P=.02$ and $P=.04$, respectively; Figure $3, B$ and $C$ ). There was no significant difference between the groups in terms of quality of life assessed by the ITQOL-SF47 and Parenting Stress Index Short Form in mothers (Figure E1).

\section{Predictors of Efficacy}

We next investigated independent predictors of cardiac functional efficacy of CDC infusion (Figure 3, D-F). Younger age was strongly associated with greater improvement of right ventricular ejection fraction measured by echocardiography $(r=-0.91 ; P=.005)$. We also found that lower weight-for-age $z$ score and reduced ejection fraction at infusion were the predictors of cardiac functional improvements 36 months after CDC infusion $(r=-0.88$; $P=.009 ;$ and $r=-0.90 ; P=.006$; respectively). 
TABLE 2. Clinical outcomes and catheter intervention during 36month follow-up

\begin{tabular}{|c|c|c|c|}
\hline & Control & CDCs & $\begin{array}{c}P \\
\text { value }\end{array}$ \\
\hline \multicolumn{4}{|l|}{ Adverse events } \\
\hline Late failure & 2 & 0 & .23 \\
\hline NYHA class III-IV & 1 & 0 & .50 \\
\hline PLE and plastic bronchitis & 1 & 0 & .50 \\
\hline Takedown & 0 & 0 & \\
\hline Transplant & 0 & 0 & \\
\hline Death & 0 & 0 & \\
\hline Cardiopulmonary resuscitation & 1 & 0 & .50 \\
\hline Supraventricular tachycardia & 0 & 0 & \\
\hline Pacemaker implantation & 0 & 0 & \\
\hline Prolonged chest tube drainage & 1 & 0 & .50 \\
\hline Cirrhosis & 0 & 0 & \\
\hline Thromboembolic events & 0 & 0 & \\
\hline Stroke & 0 & 0 & \\
\hline Tumor formation & 0 & 0 & \\
\hline $\begin{array}{l}\text { Any type of unplanned catheter intervention } \\
\text { (N/person-y) }\end{array}$ & 1.43 & 0.52 & .04 \\
\hline APC coils (N/person-y) & 0.86 & 0.24 & .10 \\
\hline Balloon angioplasty (N/person-y) & 0.57 & 0.29 & .25 \\
\hline Pulmonary artery (N/person-y) & 0.43 & 0.14 & .17 \\
\hline Aortic $\operatorname{arch}(\mathrm{N} /$ person-y) & 0.05 & 0.05 & \\
\hline Fenestration (N/person-y) & 0.10 & 0.05 & .53 \\
\hline
\end{tabular}

\section{DISCUSSION}

Since the first case of autologous mononuclear bone marrow cell (BMC) transplantation for acute myocardial infarction was reported in 2001, numerous clinical studies with various types of stem cells have been performed to investigate the effects of stem cell therapy, mainly in adult patients with ischemic heart disease. ${ }^{14}$ Recent metaanalyses of intracoronary application of BMCs revealed modest but significant improvement of left ventricular function after myocardial infarction and a reduced incidence of death and major adverse events, although these benefits were mixed or absent in several studies. ${ }^{15}$ Among these numerous reports, limited studies have reported long-term outcomes after BMC administration for ischemic heart disease and dilated cardiomyopathy. ${ }^{16-22}$ Five of these studies have shown long-term benefits in left ventricular function and quality of life $\mathrm{e}^{16,17,20-22}$; however, the other reports revealed no evidence of sustained improvement of left ventricular performance. ${ }^{18,19}$ These controversies regarding the effect of noncardiac progenitors such as BMCs led to the investigation of new cell types, including CDCs.

Recent studies have shown that, among various cell types, CDCs exhibit a balanced profile of paracrine factor secretion and the greatest myocardial regeneration potential. ${ }^{23,24}$ In clinical trials, cardiac progenitors showed improvement of left ventricular ejection fraction in the Cardiac Stem Cell
TABLE 3. Hemodynamics by catheterization study at final follow-up and Fontan operative characteristics

\begin{tabular}{|c|c|c|c|}
\hline & Control & CDCs & $P$ value \\
\hline \multicolumn{4}{|l|}{ Hemodynamics } \\
\hline Mean PA pressure $(\mathrm{mm} \mathrm{Hg})$ & $11.9 \pm 1.9$ & $12.1 \pm 1.3$ & .75 \\
\hline RVEDP (mm Hg) & $7.2 \pm 1.7$ & $6.6 \pm 1.1$ & .47 \\
\hline PVRI (Wood units $\cdot \mathrm{m}^{2}$ ) & $2.1 \pm 0.7$ & $1.8 \pm 0.4$ & .31 \\
\hline Cardiac index $\left(\mathrm{L} / \mathrm{min} / \mathrm{m}^{2}\right)$ & $3.6 \pm 0.6$ & $4.9 \pm 0.9$ & .02 \\
\hline Fontan operation performed & 6 & 7 & .50 \\
\hline Age at Fontan (y) & $3.0 \pm 0.8$ & $3.0 \pm 0.6$ & .97 \\
\hline $\begin{array}{l}\text { Interval between } \\
\text { bidirectional Glenn and } \\
\text { Fontan (y) }\end{array}$ & $2.5 \pm 0.8$ & $2.4 \pm 0.4$ & .77 \\
\hline $\begin{array}{l}\text { Follow-up period after } \\
\text { Fontan (mo) }\end{array}$ & $20.1 \pm 13.0$ & $24.9 \pm 14.2$ & .63 \\
\hline $\begin{array}{l}\text { Fontan type (extracardiac } \\
\text { conduit) }\end{array}$ & 6 & 7 & \\
\hline Creation of fenestration & 6 & 7 & \\
\hline \multicolumn{4}{|l|}{$\begin{array}{l}\text { Concomitant procedures } \\
\text { performed }\end{array}$} \\
\hline None & 2 & 2 & .66 \\
\hline Arch augmentation & 0 & 2 & .27 \\
\hline Tricuspid valve repair & 3 & 1 & .22 \\
\hline Atrial septectomy & 0 & 0 & \\
\hline PA patch augmentation & 1 & 3 & .34 \\
\hline
\end{tabular}

Data represent number or mean \pm SD. Final follow-up catheterization studies were performed from 30 to 36 months of follow-up. $C D C$, Cardiosphere-derived cell; $P A$, pulmonary artery; $R V E D P$, right ventricular end-diastolic pressure; $P V R I$, pulmonary vascular resistance index.

Infusion in Patients With Ischemic Cardiomyopathy (SCIPIO) trial and the reduction in scar mass in the Cardiosphere-Derived Autologous Stem Cells to Reverse Ventricular Dysfunction (CADUCEUS) trial in patients with ischemic heart disease, ${ }^{25,26}$ whether the benefit for ventricular function or regeneration after cardiac progenitor infusion could be maintained in the long term has remained unknown.

The clinical outcome of patients with Fontan circulations who require mechanical circulatory support as a bridge to heart transplant is still poor; in addition, their survival after transplant was the worst among patients with congenital heart disease. ${ }^{27}$ Under these circumstances, clinical studies of cell therapy for pediatric patients have been limited to case reports, including 1 case of HLHS, until the initial results of the TICAP trial were reported recently. ${ }^{28,29}$ To our knowledge, this study is the first on the midterm outcomes of CDC infusion in pediatric patients.

In this 3-year follow-up study, no side effects, including tumor formation, were observed during 36 months of follow-up. Beneficial effects, such as improvement of right ventricular function with reduced tricuspid annular diameter, could be observed at 36 months. It has been demonstrated that CDCs are present in a much larger number in the heart and have stronger regenerative ability in younger children than in adults. ${ }^{30}$ Interestingly, 
controls - CDCs
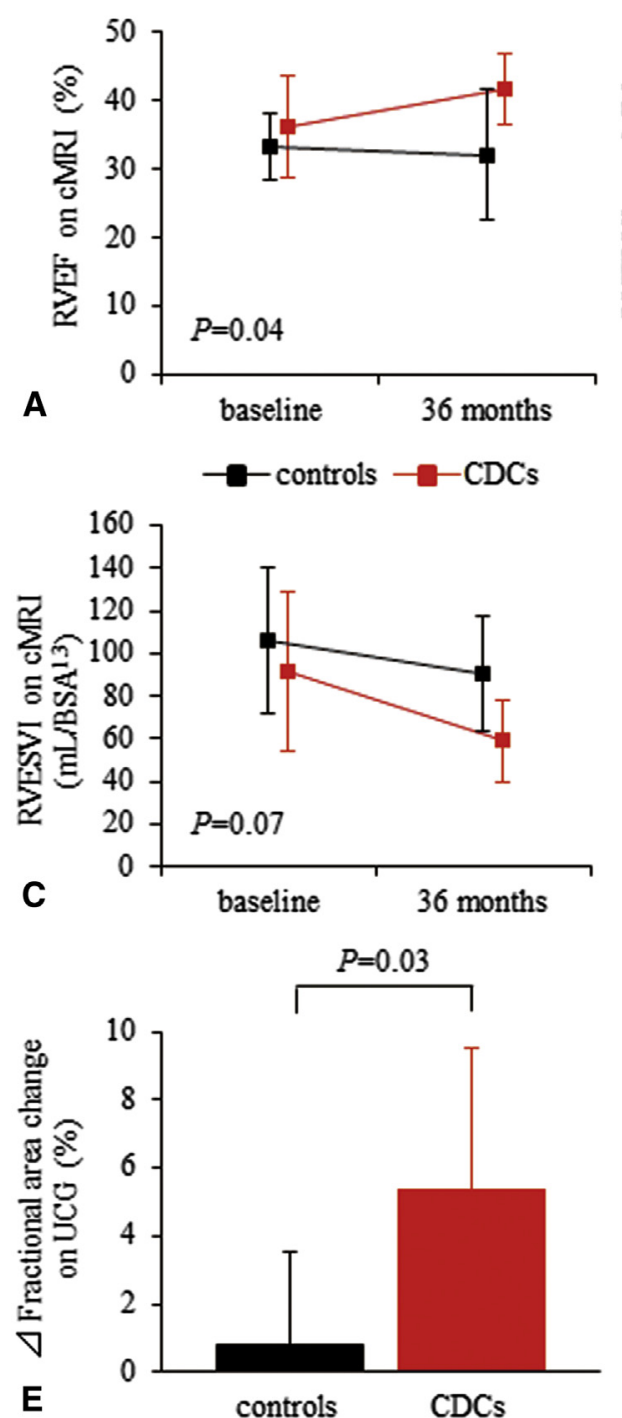

E

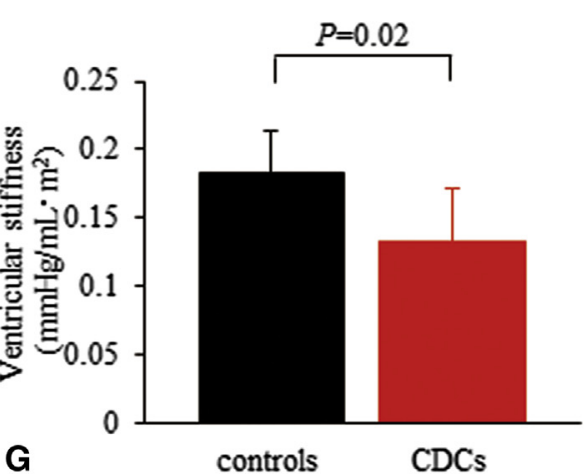

controls CDCs
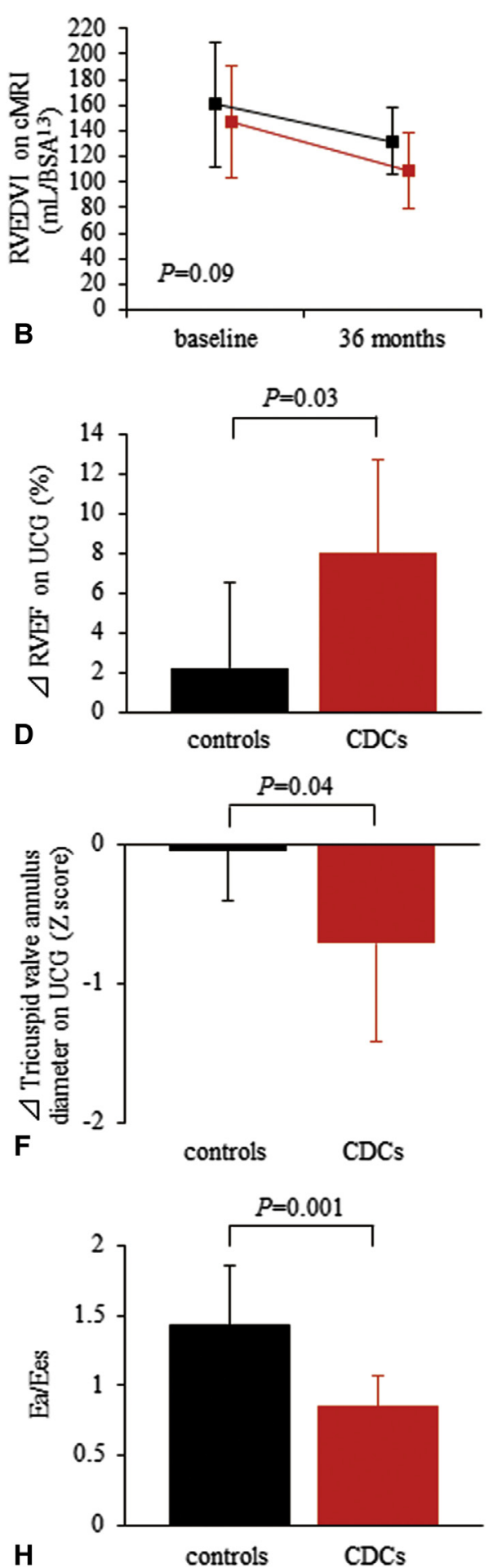

FIGURE 2. Cardiac magnetic resonance imaging ( $c M R I)$ and echocardiographic analyses in control and cardiosphere-derived cell ( $C D C)$-treated groups at 36 months of follow-up. A through C, Right ventricular ejection fraction $(R V E F ; \mathrm{A})$; right ventricular end-diastolic volume index (RVEDVI) for body surface $\operatorname{area}^{1.3}\left(B S A^{1.3} ; \mathrm{B}\right)$; and right ventricular end-systolic volume index $(R V E S V I)$ for body surface area ${ }^{1.3}(\mathrm{C})$ measured by cMRI in the control and the cardiosphere-derived cell-treated groups at baseline and 36 months of follow-up are shown. D through F, Absolute changes in right ventricular ejection fraction $(\triangle R V E F$; D); fractional area change $(\mathrm{E})$; and tricuspid valve annular diameter assessed by $z$ score $(\mathrm{F})$ measured by echocardiography $(U C G)$ at 36 months of follow-up are shown. $\mathrm{G}$ and $\mathrm{H}$, Ventricular stiffness $(\mathrm{G})$ and ventriculoarterial coupling $(\mathrm{H})$, the ratio of effective arterial elastance $(E a)$, to end-systolic elastance (Ees), measured by catheterization study at final follow-up from 30 to 36 months are demonstrated. Data are shown as mean \pm SD. 

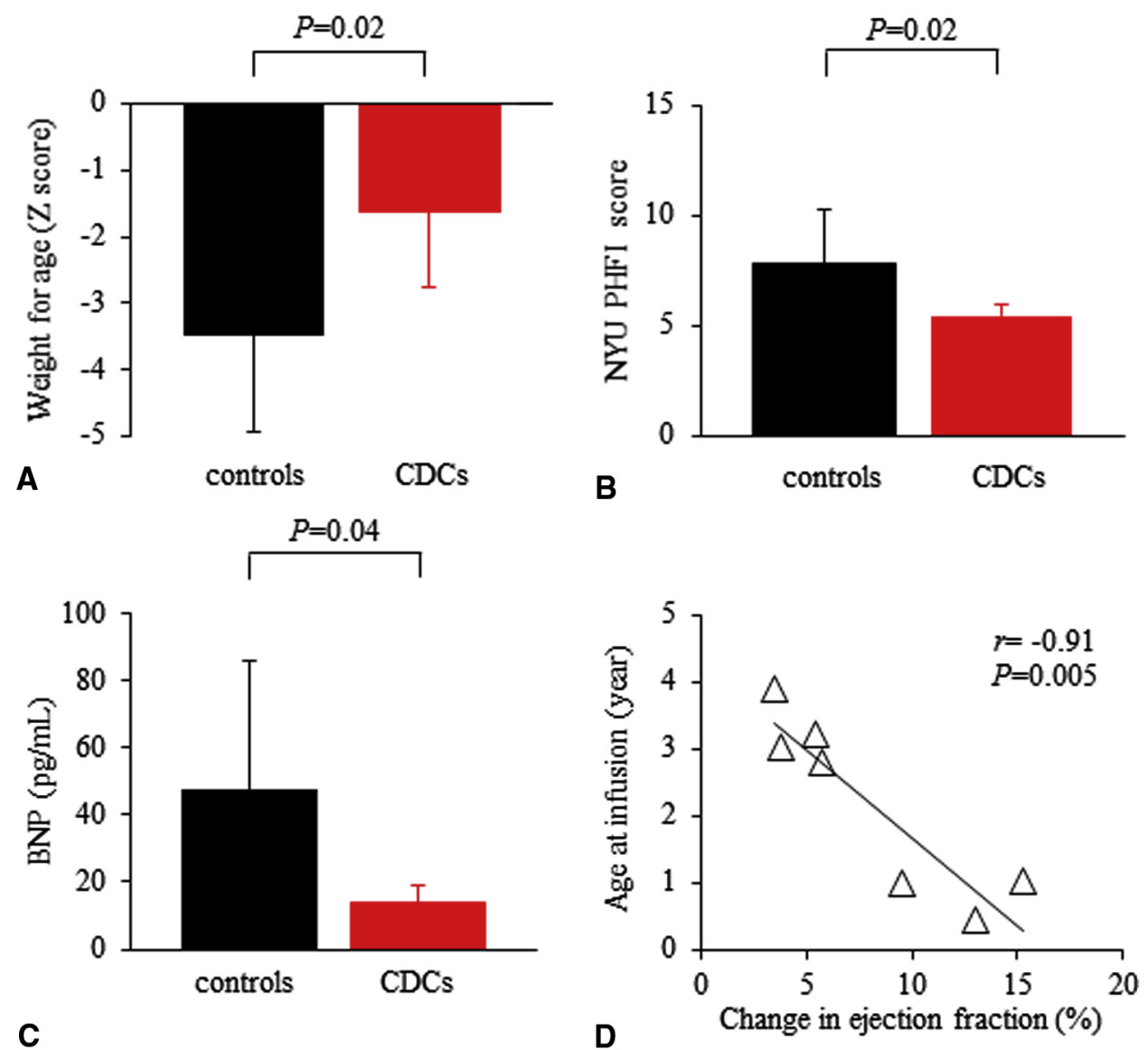

C Changes in ejection fraction (\%)
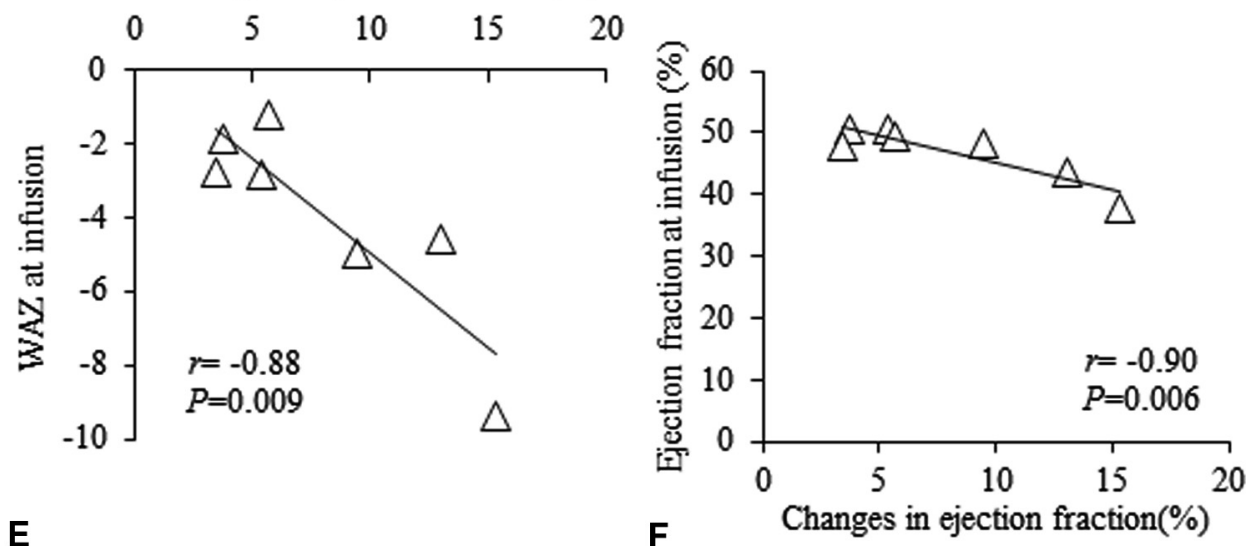

FIGURE 3. Somatic growth, functional status, and clinical outcomes during 3-year observation of Transcoronary Infusion of Cardiac Progenitor Cells in Patients with Single-Ventricle Physiology trial. A through C, Weight for age corrected by $z$ score (A); New York University Pediatric Heart Failure Index (NYU PHFI) scores (B); and serum brain natriuretic peptide (BNP) levels (C) in the control and cardiosphere-derived cell (CDC)-treated groups at 36 months of follow-up are shown. Data are shown as mean \pm SD. D through F, Correlation between changes in right ventricular ejection fraction and age at infusion (D); weight for age $z$ score (WAZ; E); and right ventricular ejection fraction at infusion (F) are shown.

greater improvement in cardiac function was detected in patients with a younger age or a low weight-for-age $z$ score, which also supports this hypothesis. Because recent report has suggested that growth hormonereleasing hormone may stimulate cardiac stem cell selfrenewal to support myocardial repair, targeting the age- dependent CDC-secreted effectors could be a novel therapeutic approach. ${ }^{31}$

Although ejection fraction is a valuable measurement to determine ventricular function, as many as $50 \%$ of patients with heart failure have a preserved ejection fraction, and most of them show diastolic dysfunction. Increased 
ventricular stiffness is a distinct finding in those patients. ${ }^{32}$ Ventricular diastolic stiffness also affects morbidity, particularly the duration of pleural effusions after the Fontan operation. ${ }^{33}$ In our study, ventricular stiffness, which could be associated with myocardial fibrosis, was lower in the CDC-treated group at the final follow-up, indicating that the beneficial effect of cell transfusion on diastolic function may improve ventriculoarterial coupling, leading to superior mechanical efficiency relative to that in the control group. $^{34}$

In our midterm follow-up study, no late adverse events were observed in the CDC-treated group, whereas several complications were seen in the control group. Although the difference in the number of patients was not significant, the relatively good clinical course of the CDC-treated group may have been due to the improved ventricular function as well as better diastolic function. Moreover, sustained improvement in cardiac function resulted in significant reduction of heart failure symptoms and better somatic growth in the midterm. Importantly, we found that the reactivity of CDC infusion was greater in patients with lower cardiac function. When we look at the patients in detail, the CDC-treated patient with the lowest right ventricular ejection fraction at baseline within the group showed a remarkable increase in ejection fraction after CDC infusion, and improved cardiac function was preserved at 36 months of follow-up (37.9\% at baseline to $47.4 \%$ at 3 months and $53.2 \%$ at 36 months). This patient underwent the Fontan operation 27 months after a bidirectional Glenn procedure and has been doing well without heart failure symptoms during midterm follow-up. In contrast, the patient in the control group with the lowest RVEF at baseline showed no improvement in RVEF during the follow-up period (39.3\% at baseline to $38.0 \%$ at 3 months and $32.2 \%$ at 36 months) and has not had the Fontan operation completed yet because of heart failure. These data indicate that CDC infusion may have the potential to become an alternative medicine or bridge to transplant for severe heart failure in patients with single-ventricle physiology.

Because no studies have yet reported impaired ventricular function as a risk factor of catheter intervention or APCA coil embolization, the mechanisms underlying the lower incidence of catheter interventions and higher degree of freedom from APCA coil embolization in the CDCtreated group are not clear. It could be anticipated that a lower incidence of catheter intervention might result in better quality of life for patients and greater reduction in medical costs. Further studies are necessary to elucidate these clinically remarkable observations.

\section{Study Limitations}

The study was a small, nonrandomized, phase 1 study, not powered to assess efficacy in a definitive manner. The cardiac interventionists were not blinded to allocation of
CDC infusion because of the lack of placebo infusion in control group. There may have been sufficient imbalance in preregistration covariates between the groups to affect the clinical outcomes of primary interest that may need to be adjusted in future trials. The efficacy prediction was assessed by bivariate analysis with limited variables in small sample size, and the results should therefore be interpreted with caution. Although the morphology of all of the patients was HLHS, there was a mixture of patients after the Fontan operation and the bidirectional Glenn procedure. Most of the patients after the bidirectional Glenn procedure underwent the Fontan operation during the follow-up period, which also may have affected outcome measures, including right ventricular volume and the incidences of catheter intervention and coil embolization. In the cMRI study, we did not assess myocardial fibrosis by late gadolinium enhancement, suggested by a recent study as a potential contributor to ventricular dysfunction in patients with single-ventricle physiology, which remains to be elucidated in future phase 2 clinical trials. ${ }^{35}$

\section{CONCLUSIONS}

This is the first clinical trial of midterm outcomes of CDC infusion in pediatric patients with HLHS. The results of our study demonstrate the safety and feasibility of intracoronary infusion of autologous CDCs in infants with HLHS. Improved ventricular function was maintained during 36 months of observation, which resulted in improvement of heart failure status in the midterm. Larger phase 2 studies focusing on changes in cardiac function, myocardial fibrosis, quality of life, and clinical event rates are warranted to confirm these effects of CDC administration in patients with single-ventricular physiology.

\section{Conflict of Interest Statement}

Authors have nothing to disclose with regard to commercial support.

You can watch a Webcast of this AATS meeting presentation by going to: http://webcast.aats.org/2015/Video/ Monday/04-27-15_4E_1025_Sano.mp4

We thank Dr Shiro Hinotsu (Okayama University Hospital) for critical review of the statistical analysis.

\section{References}

1. De Rita F, Crossland D, Griselli M, Hasan A. Management of the failing Fontan. Semin Thorac Cardiovasc Surg Pediatr Card Surg Annu. 2015;18:2-6.

2. Sano S, Ishino K, Kado H, Shiokawa Y, Sakamoto K, Yokota M, et al. Outcome of right ventricle-to-pulmonary artery shunt in first-stage palliation of hypoplastic left heart syndrome: a multi-institutional study. Ann Thorac Surg. 2004;78: 1951-7; discussion 1957-8.

3. d'Udekem Y, Iyengar AJ, Cochrane AD, Grigg LE, Ramsay JM, Wheaton GR, et al. The Fontan procedure: contemporary techniques have improved longterm outcomes. Circulation. 2007;116(11 Suppl):I157-64.

4. Rychik J, Goldberg DJ. Late consequences of the Fontan operation. Circulation. 2014;130:1525-8. 
5. Anderson JB, Kalkwarf HJ, Kehl JE, Eghtesady P, Marino BS. Low weight-forage $z$-score and infection risk after the Fontan procedure. Ann Thorac Surg. 2011; 91:1460-6.

6. Piran S, Veldtman G, Siu S, Webb GD, Liu PP. Heart failure and ventricular dysfunction in patients with single or systemic right ventricles. Circulation. 2002;105:1189-94.

7. Hosein RB, Clarke AJ, McGuirk SP, Griselli M, Stumper O, De Giovanni JV, et al. Factors influencing early and late outcome following the Fontan procedure in the current era. The 'Two Commandments'? Eur J Cardiothorac Surg. 2007; 31:344-52; discussion 353.

8. Iyengar AJ, Winlaw DS, Galati JC, Wheaton GR, Gentles TL, Grigg LE, et al; Australia and New Zealand Fontan Registry. The extracardiac conduit Fontan procedure in Australia and New Zealand: hypoplastic left heart syndrome predicts worse early and late outcomes. Eur J Cardiothoracic Surg. 2014;46: 465-73; discussion 473

9. Ishigami S, Ohtsuki S, Tarui S, Ousaka D, Eitoku T, Kondo M, et al. Intracoronary autologous cardiac progenitor cell transfer in patients with hypoplastic left heart syndrome: the TICAP prospective phase 1 controlled trial. Circ Res. 2015;116:653-64.

10. Connolly D, Rutkowski M, Auslender M, Artman M. The New York University Pediatric Heart Failure Index: a new method of quantifying chronic heart failure severity in children. J Pediatr. 2001;138:644-8.

11. Vogt KN, Manlhiot C, Van Arsdell G, Russell JL, Mital S, McCrindle BW. Somatic growth in children with single ventricle physiology impact of physiologic state. J Am Coll Cardiol. 2007;50:1876-83.

12. McCrindle BW, Zak V, Sleeper LA, Paridon SM, Colan SD, Geva T, et al; Pediatric Heart Network Investigators. Laboratory measures of exercise capacity and ventricular characteristics and function are weakly associated with functional health status after Fontan procedure. Circulation. 2010;121:34-42.

13. Farel AM, Hooper SR. Relationship between the Maternal Social Support Index and the Parenting Stress Index in mothers of very-low-birthweight children now age 7. Psychological reports. 1998;83:173-4.

14. Ptaszek LM, Mansour M, Ruskin JN, Chien KR. Towards regenerative therapy for cardiac disease. Lancet. 2012;379:933-42.

15. Jeevanantham V, Butler M, Saad A, Abdel-Latif A, Zuba-Surma EK, Dawn B. Adult bone marrow cell therapy improves survival and induces long-term improvement in cardiac parameters: a systematic review and meta-analysis. Circulation. 2012;126:551-68.

16. Yousef M, Schannwell CM, Köstering M, Zeus T, Brehm M, Strauer BE. The BALANCE Study: clinical benefit and long-term outcome after intracoronary autologous bone marrow cell transplantation in patients with acute myocardial infarction. J Am Coll Cardiol. 2009;53:2262-9.

17. Cao F, Sun D, Li C, Narsinh K, Zhao L, Li X, et al. Long-term myocardial functional improvement after autologous bone marrow mononuclear cells transplantation in patients with ST-segment elevation myocardial infarction: 4 years follow-up. Eur Heart J. 2009;30:1986-94.

18. Meyer GP, Wollert KC, Lotz J, Pirr J, Rager U, Lippolt P, et al. Intracoronary bone marrow cell transfer after myocardial infarction: 5-year follow-up from the randomized-controlled BOOST trial. Eur Heart J. 2009;30:2978-84.

19. Beitnes JO, Hopp E, Lunde K, Solheim S, Arnesen H, Brinchmann JE, et al. Long-term results after intracoronary injection of autologous mononuclear bone marrow cells in acute myocardial infarction: the ASTAMI randomised, controlled study. Heart. 2009;95:1983-9.

20. Assmus B, Leistner DM, Schächinger V, Erbs S, Elsässer A, Haberbosch W, et al; REPAIR-AMI Study Group. Long-term clinical outcome after intracoronary application of bone marrow-derived mononuclear cells for acute myocardial infarction: migratory capacity of administered cells determines event-free survival. Eur Heart J. 2014;35:1275-83.

21. Seth S, Bhargava B, Narang R, Ray R, Mohanty S, Gulati G, et al; AIIMS Stem Cell Study Group. The ABCD (Autologous Bone Marrow Cells in Dilated Cardiomyopathy) trial a long-term follow-up study. J Am Coll Cardiol. 2010;55: 1643-4.

22. Vrtovec B, Poglajen G, Lezaic L, Sever M, Domanovic D, Cernelc P, et al. Effects of intracoronary $\mathrm{CD} 34^{+}$stem cell transplantation in nonischemic dilated cardiomyopathy patients: 5-year follow-up. Circ Res. 2013;112:165-73.

23. Chimenti I, Smith RR, Li TS, Gerstenblith G, Messina E, Giacomello A, et al. Relative roles of direct regeneration versus paracrine effects of human cardiosphere-derived cells transplanted into infarcted mice. Circ Res. 2010; 106:971-80.

24. Amodio V, Tevy MF, Traina C, Ghosh TK, Capovilla M. Transactivation in Drosophila of human enhancers by human transcription factors involved in congenital heart diseases. Dev Dyn. 2012;241:190-9.
25. Bolli R, Chugh AR, D'Amario D, Loughran JH, Stoddard MF, Ikram S, et al. Cardiac stem cells in patients with ischaemic cardiomyopathy (SCIPIO): initial results of a randomised phase 1 trial. Lancet. 2011;378:1847-57.

26. Makkar RR, Smith RR, Cheng K, Malliaras K, Thomson LE, Berman D, et al, Intracoronary cardiosphere-derived cells for heart regeneration after myocardial infarction (CADUCEUS): a prospective, randomised phase 1 trial. Lancet. 2012; 379:895-904.

27. Lamour JM, Kanter KR, Naftel DC, Chrisant MR, Morrow WR, Clemson BS, et al; Pediatric Heart Transplant Study. The effect of age, diagnosis, and previous surgery in children and adults undergoing heart transplantation for congenital heart disease. J Am Coll Cardiol. 2009;54:160-5.

28. Tarui $\mathrm{S}$, Sano S, Oh H. Stem cell therapies in patients with single ventricle physiology. Methodist DeBakey Cardiovasc J. 2014;10:77-81.

29. Heng JC, Feng B, Han J, Jiang J, Kraus P, Ng JH, et al. The nuclear receptor $\mathrm{Nr} 5 \mathrm{a} 2$ can replace Oct4 in the reprogramming of murine somatic cells to pluripotent cells. Cell Stem Cell. 2010;6:167-74.

30. Bellsham-Revell HR, Tibby SM, Bell AJ, Witter T, Simpson J, Beerbaum P, et al. Serial magnetic resonance imaging in hypoplastic left heart syndrome gives valuable insight into ventricular and vascular adaptation. J Am Coll Cardiol. 2013;61:561-70.

31. Florea V, Majid SS, Kanashiro-Takeuchi RM, Cai RZ, Block NL, Schally AV, et al. Agonists of growth hormone-releasing hormone stimulate self-renewal of cardiac stem cells and promote their survival. Proc Natl Acad Sci U S A. 2014;111:17260-5.

32. Westermann D, Kasner M, Steendijk P, Spillmann F, Riad A, Weitmann K, et al Role of left ventricular stiffness in heart failure with normal ejection fraction. Circulation. 2008;117:2051-60.

33. Garofalo CA, Cabreriza SE, Quinn TA, Weinberg AD, Printz BF, Hsu DT, et al. Ventricular diastolic stiffness predicts perioperative morbidity and duration of pleural effusions after the Fontan operation. Circulation. 2006;114(1 Suppl):I56-61.

34. Zile MR, Baicu CF, Ikonomidis JS, Stroud RE, Nietert PJ, Bradshaw AD, et al Myocardial stiffness in patients with heart failure and a preserved ejection fraction: contributions of collagen and titin. Circulation. 2015;131:1247-59.

35. Rathod RH, Prakash A, Powell AJ, Geva T. Myocardial fibrosis identified by cardiac magnetic resonance late gadolinium enhancement is associated with adverse ventricular mechanics and ventricular tachycardia late after Fontan operation. $J$ Am Coll Cardiol. 2010;55:1721-8.

Key Words: stem cell therapy, cardiosphere, hypoplastic left heart syndrome, heart failure, congenital heart disease

\section{Discussion}

Dr John E. Mayer, Jr (Boston, Mass). Dr Sano, thank you for bringing this very well conducted and exhaustively studied and analyzed report on the 3-year results of your phase 1 trial of intracoronary infusion of autologous CDCs in patients with HLHS. There did not seem to have been any adverse effects of these cell infusions, and the data clearly suggest that there is a benefit in terms of late right ventricular function.

There is actually little to criticize about this trial other than that it wasn't randomized, but it wasn't intended to be a randomized trial. There are complete baseline and follow-up data for all 14 patients who were studied. There were some differences between the control and treated groups, and patients in both groups entered the trial at different points in their staged HLHS management. In particular, 4 patients in the treated group received their CDC infusions after the Fon$\tan$ operation, whereas there were only 2 patients in the control group who had undergone the Fontan operation at the time of entry into the study. Also, the means of multiple variables were compared between the 2 groups, rather than having each patient serve as his or her own control. 
That leads me to several questions. First, because you have a complete data set but a relatively small number of patients, I wonder what the data would look like if you used each patient as his or her own control and then compared the mean changes for each group for each of the outcome variables?

Dr Sano. Dr Mayer, thank you for your comment. First, I must say that we understand the number of patients in the TICAP trial were so small; however, the Ministry of Health of Japan requested us to perform the phase 1 trial with only 7 patients. Now, when we look at the data of right ventricular function compared with baseline within each group, RVEF assessed by echocardiography was significantly improved from $47 \%$ to $55 \%$ in the CDC-treated group at 36-month follow-up. By contrast, no significant improvement was found in the control group. In addition, the ventricular stiffness, which reflects diastolic dysfunction, tended to increase from baseline in both groups.

These data suggest that the CDC infusion improves systolic function and prevents progression of diastolic dysfunction of a single right ventricle. Although some data, including brain natriuretic peptide and body weight, did not have a significant improvement, we speculate that these changes will become significant if the sample number is increased.

Dr Mayer. You have pointed out that the CDC-treated patients had a lower incidence of interventional catheterizations to coil APCAs. Do you think that this was because more of the control patients were in the pre-Fontan phase of their staged management, or do you have other ideas about how the CDC infusions could affect the development of APCAs?

Dr Sano. Yes, we think that is one of the main reasons, that more of the control patients were in the pre-Fontan phase, as you mentioned. Because no studies have yet reported impaired ventricular function as a risk factor of catheter intervention or APCA coil embolization, the mechanisms underlying the lower incidence of catheter intervention and higher degree of freedom from APCA coil embolization in the CDC-treated group are not clear so far.

There might be some correlation between CDC infusion and APCA development; however, we don't know the real reason that CDC infusion could affect the development of APCAs.

Dr Mayer. I have 2 more questions. You have noted that the positive effects of the cell infusions varied by patient age and their weight $z$ scores, with more benefit to the younger and smaller patients. Can you speculate on why the most positive effects were observed in the youngest patients and the mechanisms by which these infusions could lead to improved ventricular function? In particular, do you think that the CDCs themselves are different when they are coming from the younger patients or that the destination in the myocardium is different in the younger patients?

Dr Sano. Our previous studies have shown that infants have 4-fold more human CDCs than adults. Another group has demonstrated that human CDCs isolated from neonates show a much stronger regenerative ability both in vitro and in vivo, including enhanced cardiomyogenic and angiogenic function compared with adult-derived CDCs. These data seem to suggest that the younger children have a greater potential for myocardial regeneration.

Initially, stem cells were believed to promote cardiac regeneration through direct differentiation into cardiac cells, but more recent studies have revealed that direct differentiation is only a part of the mechanism. In addition to that, cell transplantation stimulates endogenous cardiac repair process and angiogenesis through paracrine signaling, direct cell-to-cell interaction, which promotes myocyte cell cycling. So it is obvious that we have to continue to enhance our understanding of both cellular and molecular mechanisms underpinning cardiac repair with stem cell therapy.

Dr Mayer. And the last question is, how will this observation that the most positive effects were observed in the youngest patients affect the design of your anticipated phase 3 trial?

Dr Sano. Thank you. Theoretically, infants and younger children with severe heart failure are the best candidates for cardiac stem cell therapy. The phase 1 trial was limited to only 7 patients, but the phase 2 study is ongoing with 34 patients in our hospital. It is a randomized trial and is recruiting patients with relatively reduced cardiac function. After analysis of the result of the phase 2 study, we think that the appropriate age, body weight, and ventricular function for the candidate will become clear. Once the government approves the phase 2 trial, we will proceed to phase 3 , which is a multicenter study, and in phase 3 we will be able to compare the results, including even neonates and small infants.

Dr Mayer. It thank the Association for the opportunity to discuss this article.

Dr Todd Rosengart (Houston, Tex). Congratulations on a nice presentation. I have a quick question. I think, as you know, the intracoronary route of delivery has been very difficult for biologics, be it gene therapy, viruses, or even cells. In fact, most clinical trials with intracoronary delivery have shown negative results. Just today the Efficacy and Safety Study of Genetically Targeted Enzyme Replacement Therapy for Advanced Heart Failure (CUPID) trial was announced as a negative result looking at adeno-associated virus-mediated delivery of the transgene SERCA2a.

So the question I have for you is, either in preclinical data or in your clinical study, is there any evidence in terms of the percentage uptake of the CDC cells or how much overtaking of the native myocardium occurs with the CDC cells? In other words, in your hands, what is the efficiency of your delivery methodology?

Dr Sano. Thank you for the question. It is a very difficult question. We haven't shown what percentage of the cells are delivered, but from the clinical or the preclinical study, we think that only $3 \%$ to $5 \%$ of the cells stay. The response in the small babies is completely different from that in adults, however, so it may be that our clinical result is much better than in the adult population. 
controls $\mathrm{CDCs}$

Dontrols $\mathrm{CDCs}$
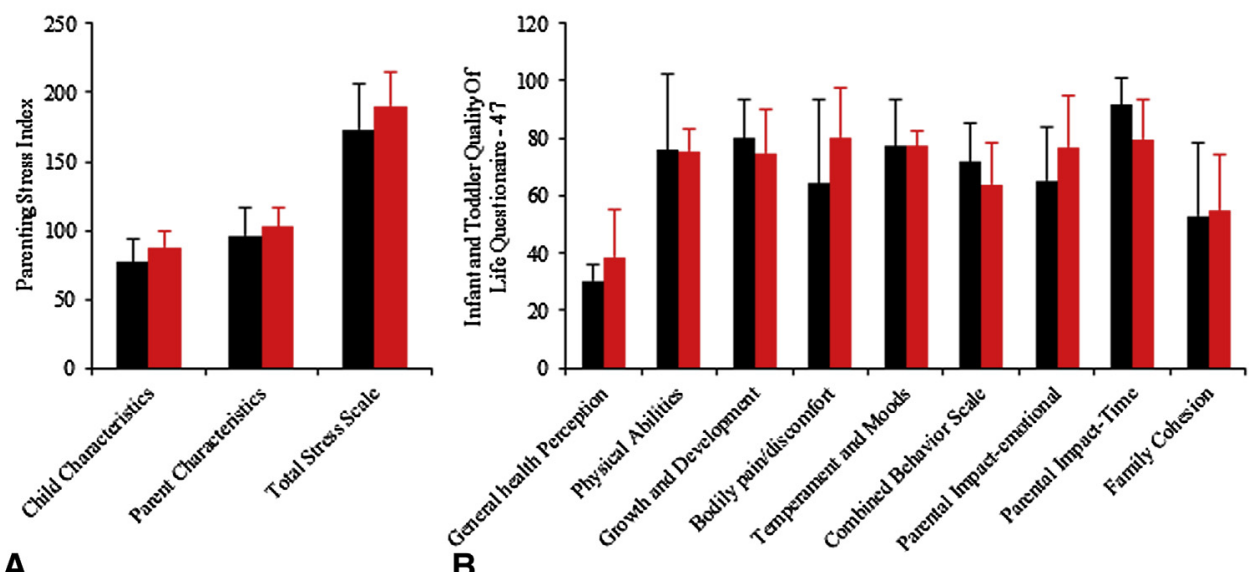

A

B

FIGURE E1. Parenting stress and quality of life at final follow-up. Parenting Stress Index (A) and score of each scale from The Infant Toddler Quality of Life Questionnaire (B) are shown. Data are shown as mean \pm SD. CDC, Cardiosphere-derived cell. 
TABLE E1. Pooled data of echocardiography- and cardiac magnetic resonance imaging-measured parameters in control and cardiosphere derived cell-treated groups

\begin{tabular}{|c|c|c|c|}
\hline & Control & CDCs & $P$ value \\
\hline \multicolumn{4}{|c|}{ Cardiac magnetic resonance imaging } \\
\hline \multicolumn{4}{|c|}{ Right ventricular ejection fraction $(\%)$} \\
\hline Baseline & $33.2 \pm 4.9$ & $36.1 \pm 7.5$ & .50 \\
\hline $18 \mathrm{mo}$ & $31.5 \pm 6.8$ & $40.4 \pm 7.6$ & .04 \\
\hline $36 \mathrm{mo}$ & $32.2 \pm 9.4$ & $41.8 \pm 5.2$ & .04 \\
\hline \multicolumn{4}{|c|}{ RVEDVI (mL/BSA $\left.{ }^{1.3}\right)$} \\
\hline Baseline & $160.4 \pm 48.6$ & $139.0 \pm 43.4$ & .48 \\
\hline $18 \mathrm{mo}$ & $150.2 \pm 41.7$ & $112.2 \pm 31.4$ & .08 \\
\hline $36 \mathrm{mo}$ & $131.8 \pm 26.4$ & $101.1 \pm 30.2$ & .08 \\
\hline \multicolumn{4}{|c|}{ RVESVI (mL/BSA $\left.{ }^{1.3}\right)$} \\
\hline Baseline & $105.7 \pm 34.3$ & $91.6 \pm 37.5$ & .55 \\
\hline $18 \mathrm{mo}$ & $103.8 \pm 36.5$ & $67.9 \pm 23.6$ & .049 \\
\hline $36 \mathrm{mo}$ & $90.6 \pm 27.4$ & $58.9 \pm 18.8$ & .03 \\
\hline \multicolumn{4}{|c|}{ Wall mass $/ \mathrm{BSA}^{1.3}\left(\mathrm{~g} / \mathrm{BSA}^{1.3}\right)$} \\
\hline Baseline & $62.0 \pm 30.4$ & $69.9 \pm 31.0$ & .69 \\
\hline $18 \mathrm{mo}$ & $40.1 \pm 14.2$ & $41.3 \pm 14.5$ & .88 \\
\hline $36 \mathrm{mo}$ & $40.0 \pm 8.4$ & $35.9 \pm 14.3$ & .55 \\
\hline \multicolumn{4}{|c|}{ Wall mass/EDV $(\mathrm{g} / \mathrm{mL})$} \\
\hline Baseline & $0.40 \pm 0.15$ & $0.49 \pm 0.08$ & .23 \\
\hline $18 \mathrm{mo}$ & $0.36 \pm 0.12$ & $0.35 \pm 0.08$ & .62 \\
\hline $36 \mathrm{mo}$ & $0.29 \pm 0.03$ & $0.36 \pm 0.13$ & .25 \\
\hline \multicolumn{4}{|c|}{ Echocardiography } \\
\hline \multicolumn{4}{|c|}{ Right ventricular ejection fraction (\%) } \\
\hline Baseline & $46.7 \pm 4.4$ & $46.9 \pm 4.6$ & .93 \\
\hline $24 \mathrm{mo}$ & $48.9 \pm 6.9$ & $54.4 \pm 2.0$ & .07 \\
\hline $30 \mathrm{mo}$ & $49.4 \pm 6.1$ & $54.1 \pm 2.3$ & .13 \\
\hline $36 \mathrm{mo}$ & $48.9 \pm 7.8$ & $54.9 \pm 2.1$ & .03 \\
\hline \multicolumn{4}{|c|}{ Fractional area change $(\%)$} \\
\hline Baseline & $33.6 \pm 3.3$ & $34.2 \pm 4.4$ & .78 \\
\hline $24 \mathrm{mo}$ & $34.1 \pm 4.3$ & $39.4 \pm 2.2$ & .01 \\
\hline $30 \mathrm{mo}$ & $33.9 \pm 4.5$ & $39.2 \pm 2.2$ & .02 \\
\hline $36 \mathrm{mo}$ & $34.4 \pm 5.1$ & $39.5 \pm 3.3$ & .046 \\
\hline \multicolumn{4}{|c|}{ Tricuspid inflow E/A ratio } \\
\hline Baseline & $1.5 \pm 0.4$ & $1.9 \pm 0.8$ & .35 \\
\hline $24 \mathrm{mo}$ & $1.7 \pm 0.3$ & $1.5 \pm 0.7$ & .39 \\
\hline $30 \mathrm{mo}$ & $1.7 \pm 0.3$ & $1.7 \pm 0.6$ & .53 \\
\hline $36 \mathrm{mo}$ & $1.6 \pm 0.4$ & $1.6 \pm 0.6$ & .87 \\
\hline \multicolumn{4}{|c|}{ Tricuspid valve annulus diameter $(z$ score $)$} \\
\hline Baseline & $2.0 \pm 0.3$ & $2.1 \pm 0.5$ & .80 \\
\hline $24 \mathrm{mo}$ & $1.9 \pm 0.6$ & $1.4 \pm 0.4$ & .08 \\
\hline $30 \mathrm{mo}$ & $1.9 \pm 0.6$ & $1.3 \pm 0.3$ & .048 \\
\hline $36 \mathrm{mo}$ & $2.0 \pm 0.6$ & $1.3 \pm 0.3$ & .03 \\
\hline
\end{tabular}

Data represent mean \pm SD. $C D C$, Cardiosphere-derived cell; $R V E D V I$, right ventricular end-diastolic volume index; $B S A$, body surface area (in $\mathrm{kg} / \mathrm{m}^{2}$ ); $R V E S V I$, right ventricular end-systolic volume index; $E D V$, end-diastolic volume; $E / A$, early transmitral flow/atrial contraction. 